\title{
Azo Dye Degradation by Recycled Waste Zero-Valent Iron Powder
}

\author{
Wellington S. Pereira and Renato S. Freire* \\ Instituto de Química, Universidade de São Paulo, CP 26077, 05513-970 São Paulo-SP, Brazil \\ Centro de Capacitação e Pesquisa em Meio Ambiente (CEPEMA/USP) Cubatão-SP, Brazil
}

\begin{abstract}
Neste trabalho é apresentado um método eficiente para a degradação de corantes, usando uma fonte de pó de ferro zero ambientalmente amigável (resíduo de um processo industrial). A influência de vários fatores experimentais (tais como: $\mathrm{pH}$, massa de ferro, tamanho de partícula, concentração do substrato, atmosfera inerte ou oxidante) sobre a eficiência do ferro zero em reduzir o grupo cromóforo e o teor de carbono orgânico total de um azocorante (Preto Remazol B) foi avaliada. O processo de degradação do corante apresentou uma cinética de primeira ordem com uma constante de $0,153 \mathrm{~min}^{-1}$. Nas condições otimizadas $\left(\mathrm{pH}=3,[\mathrm{Fe}]=5 \mathrm{~g} \mathrm{~L}^{-1}\right.$, tamanho de partícula $\leq 250 \mu \mathrm{m}$ ), este processo promoveu uma descoloração de $95 \%$ e redução de $70 \%$ na concentração de carbono orgânico total de uma solução $100 \mathrm{mg} \mathrm{L}^{-1}$ do corante. Este processo também foi empregado na degradação de um efluente industrial têxtil apresentando bons resultados e demonstrando capacidade para ser uma alternativa para a remediação de sistemas aquáticos poluídos.
\end{abstract}

In this paper an efficient method for azo dye degradation using an environmentally friendly zero-valent iron powder source is presented (iron particles discarded from a manufacturing process). The influence of several experimental parameters (such as $\mathrm{pH}$, iron mass, particle size, substrate concentration, oxidizing and inert atmospheres) on the ability of zero-valent iron to reduce the chromophoric groups and total organic carbon content of the azo dye Remazol Black B was evaluated. Kinetic studies revealed that the azo degradation by $\mathrm{Fe}^{0}$ appeared to be first-order with respect to substrate, with an observed rate constant $\left(\mathrm{k}_{\mathrm{obs}}\right)$ of $0.153 \mathrm{~min}^{-1}$. Under the optimized operational conditions $\left(\mathrm{pH} \mathrm{3},[\mathrm{Fe}]=5 \mathrm{~g} \mathrm{~L}^{-1}\right.$, iron particle size $\leq 250 \mu \mathrm{m}$ ), the iron-based process produced net a reduction in color and total organic carbon of about $95 \%$ and $70 \%$, respectively. The process was also evaluated for the degradation of textile effluent. The studied process showed good characteristics, which can make it an effective alternative for polluted aquatic system remediation.

Keywords: reductive degradation process, dye degradation, effluent treatment, Fenton's reagent

\section{Introduction}

Over the last decades, the increasing demand for dyes by the textile industry has shown a high pollutant potential. It is estimated that around $10-15 \%$ of the dyes are lost in the effluent during the dyeing processes. ${ }^{1,2}$ The discharge of highly colored synthetic dye effluents can be very damaging to the receiving water bodies, since these dyes in the water strongly absorb sunlight, which decreases the intensity of light absorbed by water plants and phytoplankton, reducing photosynthesis and the oxygenation of water reservoirs. ${ }^{3}$ Also, public perception

*e-mail: rsfreire@iq.usp.br of water quality is greatly influenced by its color. The presence of unnatural colors is esthetically unpleasant and tends to be associated with contamination. ${ }^{4}$ In addition, dyes used in the textile industry may be toxic to aquatic organisms and can be resistant to natural biological degradation. ${ }^{3,5,6}$

Due to their stability and xenobiotic nature, reactive azo dyes are not totally degraded or exhibit slow degradation by conventional wastewater biological treatment processes. ${ }^{5}$ Although the efficiency of advanced oxidation processes for degradation of recalcitrant compounds has been extensively documented, ${ }^{7-11}$ their use for removal of dyes from textile wastewater has some drawbacks, such as high operating and equipment costs. 
Zero-valent iron has been determined to be an effective material for the removal of a variety of important organic contaminants from water. ${ }^{12-18}$ The redox couple formed by zero oxidation state metallic iron $\left(\mathrm{Fe}^{0}\right)$ and dissolved aqueous $\mathrm{Fe}^{2+}$ has a standard reduction potential of -0.440 $\mathrm{V} .{ }^{19}$ This makes $\mathrm{Fe}^{0}$ a reducing agent for many redox-labile substances, including hydrogen ions, carbonate, sulfate, nitrate, and oxygen. Azo dyes can also be reduced by iron, the reduction of the chromophoric group $(-\mathrm{N}=\mathrm{N}-$ bond) by zero valent iron being thermodynamically favorable..$^{20-23}$

The main aim of this work was to promote the degradation of Remazol Black B by employing a source of iron that is environmentally friendly, has a low energy cost and is inexpensive. The effectiveness of the proposed process was evaluated by its ability to promote decreases in color and total organic carbon content. The high efficiency observed with the dye model showed that this economic, easily operated and maintained treatment process could also be employed in the remediation of a complex textile effluent.

\section{Experimental}

\section{Reagents}

Remazol Black B (C.I. Reactive Black 5, MW = 991.8 $\mathrm{g} \mathrm{mol}^{-1}$ ) was obtained from Dystar (Suzano, SP) as a commercially available dye formulation and used without further purification. This dye is a diazo type reactive dye, containing two vinyl sulfonate reactive groups, as represented by the chemical structure in Figure 1. The zero-valent iron powder was supplied by a recycling company (Renova, São Paulo, SP). This material was originally generated during the metallurgic production of automobile mechanical pieces and it is characterized as process residue. Table 1 shows the principal elements present in this material. The textile effluent was obtained from a textile industry in the Campinas region (São Paulo). The effluent was stored at $4{ }^{\circ} \mathrm{C}$ in glass flasks and used without previous filtration or any other treatment. The main characteristics of the industrial effluent are shown in Table 2. Either $\mathrm{HCl}$ or $\mathrm{NaOH}$ was used to adjust the $\mathrm{pH}$ of the solutions to the desired levels. All chemicals employed were of analytical grade and used as received; solutions were prepared with deionized water (resistivity $>18 \mathrm{M} \Omega \mathrm{cm}$, Milli-Q, Millipore Inc., USA).

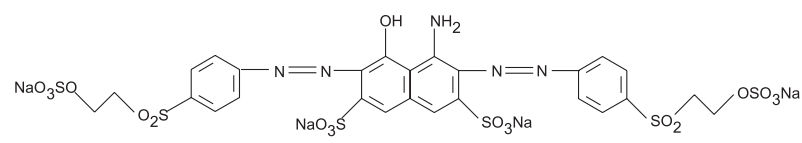

Figure 1. The chemical structure of the dye Remazol Black.
Table 1. Elements present in the recycled waste zero-valent iron powder

\begin{tabular}{lc}
\hline Element & Concentration / $\left(\mathrm{mg} \mathrm{kg}^{-1}\right)$ \\
\hline Aluminum & 125.0 \\
Antimony & $<0.01$ \\
Arsenic & $<0.01$ \\
Barium & 9.0 \\
Beryllium & 1.0 \\
Cadmium & $<0.01$ \\
Lead & $<0.01$ \\
Cobalt & $<0.01$ \\
Copper & 8.0 \\
Chromium & $<0.01$ \\
Manganese & 12.0 \\
Mercury & $<0.01$ \\
Molybdenum & 125.0 \\
Nickel & 15.0 \\
Silver & $<0.01$ \\
Selenium & $<0.01$ \\
Thallium & $<0.01$ \\
Vanadium & $<0.01$ \\
Zinc & 14.0 \\
Iron & 98.6 \\
humidity & 0.1 \\
\hline
\end{tabular}

Table 2. Physical-chemical parameters of the textile effluent

\begin{tabular}{lc}
\hline Parameter & Value \\
\hline absorbance $(\lambda=600 \mathrm{~nm})$ & 2.7 \\
$\mathrm{pH}$ & 6.0 \\
$\mathrm{COD}\left(\mathrm{mg}_{\mathrm{O} 2} \mathrm{~L}^{-1}\right)$ & 2235 \\
$\mathrm{BOD}_{5}\left(\mathrm{mg}_{\mathrm{O} 2} \mathrm{~L}^{-1}\right)$ & 760 \\
$\mathrm{TOC}^{\left(\mathrm{mg} \mathrm{L}^{-1}\right)}$ & 945 \\
\hline
\end{tabular}

\section{Zero-valent iron treatment}

Experiments were performed in an open batch system. The system consisted of a $250 \mathrm{~cm}^{-3}$ glass cylindrical reactor that housed the dye solutions or the effluent, a water cooling jacket to keep the reactor content at constant temperature $\left(20^{\circ} \mathrm{C}\right)$, a mechanical stirrer to keep the iron powder suspended (stirring rate: $500 \mathrm{rpm}$ ) and a gas disperser to bubble the solution with a stream $\left(35 \mathrm{~L} \mathrm{~h}^{-1}\right)$ of nitrogen or oxygen, providing anaerobic or aerobic conditions, respectively. At convenient intervals, samples were removed and centrifuged at 3500 for 5 minutes. The supernatant was separated and analyzed.

The recycled iron powder was separated into three different particle size ranges using meshes with pores of 350 and $250 \mu \mathrm{m}$. The iron powder surface was also treated, by reacting this material with $1 \mathrm{~mol} \mathrm{~L}^{-1} \mathrm{HCl}(1 \mathrm{~mL}$ per $100 \mathrm{mg}$ of iron) during 1 minute. The suspension was then washed and centrifuged (at $3500 \mathrm{rpm}$ during 5 minutes) to remove the residual $\mathrm{HCl}$ and $\mathrm{Fe}^{2+}$. Different amounts of iron powder were used to study its effect on the degradation efficiency. 


\section{Analytical methodology}

The efficiency of the proposed process was evaluated by monitoring dye and textile effluent decoloration, measuring absorbance at $600 \mathrm{~nm}$ using a Hitachi Model U-3000 double beam spectrophotometer. The total organic carbon (TOC) reduction was measured with a Shimadzu TOC-5000A Total Organic Analyzer, according to ISO $8245 .^{24}$ The dye content adsorbed on the iron particle surface was evaluated by using thermogravimetric methods. TG data were recorded on a Shimadzu TGA-50 thermobalance, using a platinum crucible, around $1.5 \mathrm{mg}$ of sample, dynamic air atmosphere and a heating rate of $10{ }^{\circ} \mathrm{C} \mathrm{min}^{-1}$. DSC curves were obtained on a Shimadzu DSC-50, with a dynamic nitrogen atmosphere and a heating rate of $10{ }^{\circ} \mathrm{C} \mathrm{min}^{-1}$.

\section{Results and Discussion}

The efficiency of the recycled waste zero-valent iron powder (RWZVIP) in promoting the degradation of Remazol Black B (RBB) was first investigated using $\mathrm{UV}-\mathrm{Vis}$ spectra to monitor the disappearance of this compound. RBB is a strongly absorbing dye in the UVVisible region with a distinct band in the near-UV region $(\lambda=310 \mathrm{~nm})$ and another one in the visible $(\lambda=$ $600 \mathrm{~nm}$ ). The latter, responsible for the dark blue color is due to the aromatic rings connected by azo groups and the former is associated with localized bands of the aromatic structures in the molecule. ${ }^{25}$ The absorption spectrum of a $25 \mathrm{mg} \mathrm{L}^{-1}$ air saturated RBB solution before and after a 30 minute treatment with 5 $\mathrm{g} \mathrm{L}^{-1}$ RWZVIP is presented in Figure 2. In this treatment time, the disappearance of long wavelength absorbing chromophores in the dye structure was around $97 \%$. This decoloration was mainly due to the reduction and fragmentation of the azo bonds. In spite of the excellent bleaching effect, the decay of the absorbance in the UV region was not significant, showing that the aromatic rings of $\mathrm{RBB}$ were not affected by the treatment. The spectrum modification observed in this region can be due to modification/removal of functional groups from the aromatic structures.

The RWZVIP employed in this work was from a manufacturing process, hence this material had particles with different granulation. In order to evaluate the effect of RWZVIP granule size on RBB degradation, the RWZVIP was segregated into three different granule size ranges: particles with 60 mesh $(\leq 250 \mu \mathrm{m}), 50$ mesh $(\leq 300 \mu \mathrm{m})$ and 45 mesh $(\leq 350 \mu \mathrm{m})$. Figure 3 shows the different degrees of $\mathrm{RBB}$ solution degradation as a

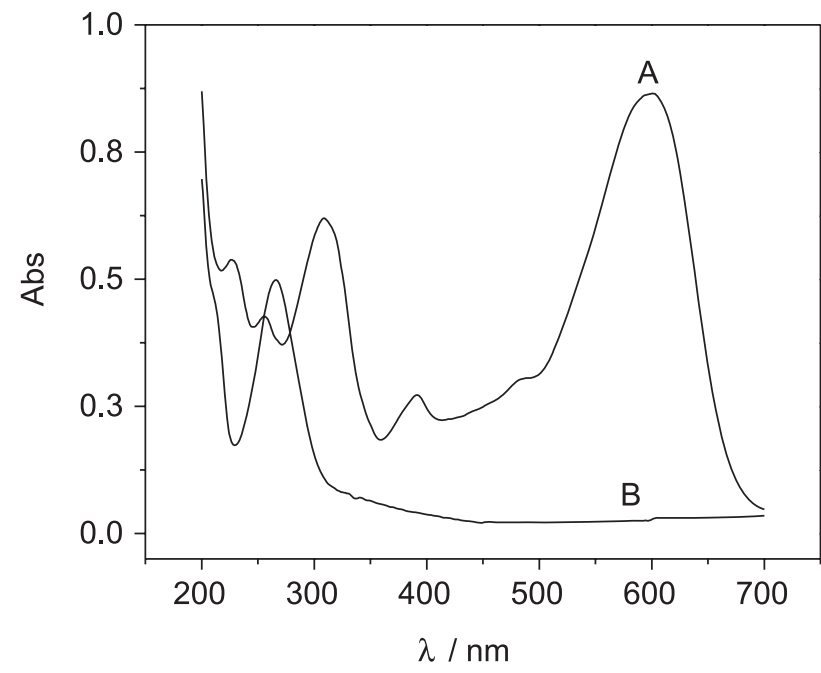

Figure 2. UV-Vis absorption spectra of a $25 \mathrm{mg} \mathrm{L}^{-1}$ Remazol Black B solution before (A) and after (B) treatment with $5 \mathrm{~g} \mathrm{~L}^{-1}$ recycled waste zero-valent iron powder. Treatment time $30 \mathrm{~min}, \mathrm{pH} \mathrm{3}$, air saturated solution.

function of RWZVIP granule size. In general, particles smaller than $300 \mu \mathrm{m}$ reduced more than $90 \%$ of the initial RBB concentration in just 15 minutes of treatment. On the other hand, particles bigger than $350 \mu \mathrm{m}$ degraded only $55 \%$. The best results were observed for particles $\leq 250 \mu \mathrm{m}$, which gave more than 97\% RBB reduction. The main mechanism of zerovalent iron degradation is the reduction of electron deficient centers, this process is dependent on electron transfer between heterogeneous phases and thus the surface area has an important effect on the reactivity. ${ }^{21,26,27}$ Further experiments were all carried out using 60 mesh RWZVIP granules, which was chosen as the optimum size to achieve the highest RBB degradation.

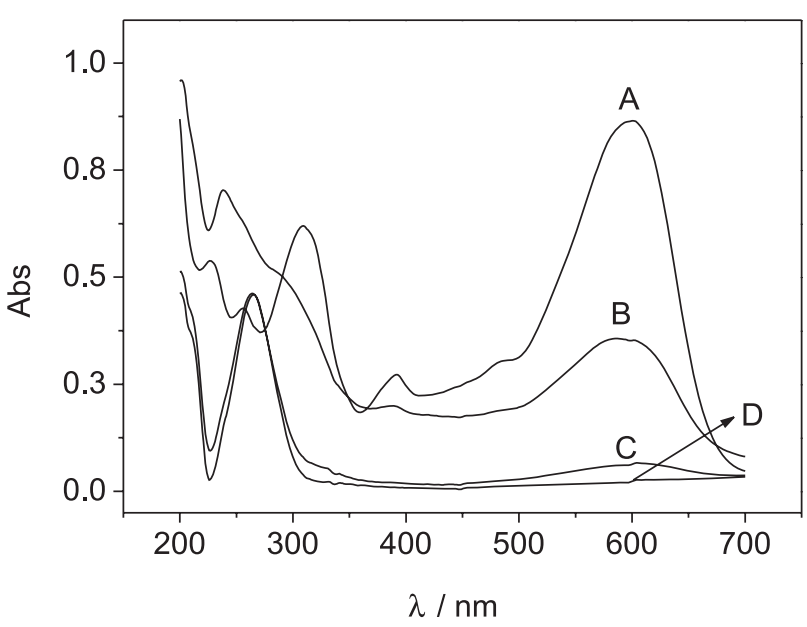

Figure 3. UV-Vis absorption spectra of a $25 \mathrm{mg} \mathrm{L}^{-1}$ Remazol Black B solution before (A) and after treatment with $5 \mathrm{~g} \mathrm{~L}^{-1}$ recycled waste zerovalent iron powder of 45 (B), 50 (C) and 60 mesh (D). Treatment time 15 min, $\mathrm{pH} 3$, air saturated solution. 
Since the degradation of $\mathrm{RBB}$ by $\mathrm{Fe}^{0}$ involves reaction at the metal surface, the quantity of metal surface has a strong influence in this process. Figure 4 shows the variation of the efficiency of RBB degradation with the amount of RWZVIP. At low iron concentrations, the degradation increased linearly with increasing amounts of $\mathrm{Fe}^{0}$, then curve levels off to a plateau above $2.5 \mathrm{~g} \mathrm{~L}^{-1}$. This profile reflects the fact that the reactive site concentration increases proportionally with RWZVIP concentration. ${ }^{28}$

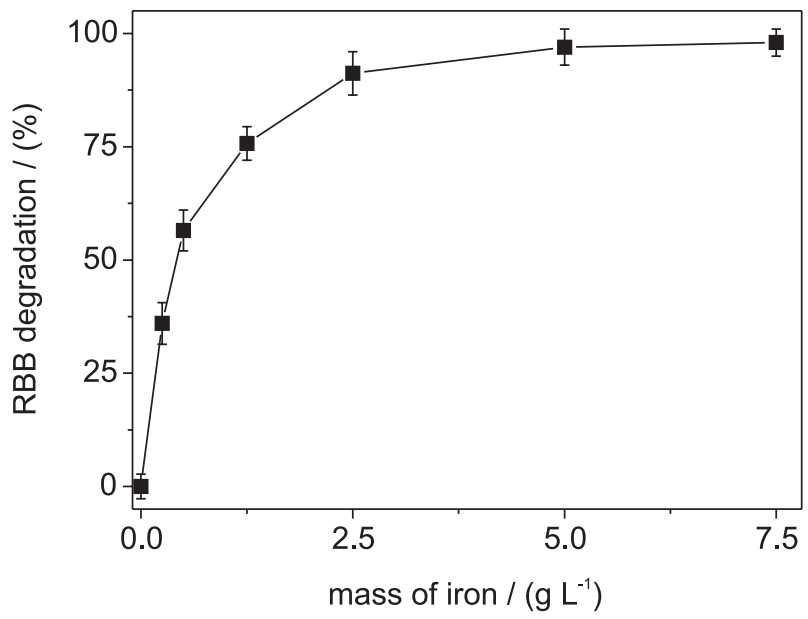

Figure 4. Effect of RWZVIP content on the degree of degradation of a $100 \mathrm{mg} \mathrm{L}^{-1} \mathrm{RBB}$ solution using 0.25 to $7.5 \mathrm{~g} \mathrm{~L}^{-1}$ of 60 mesh $\mathrm{Fe}^{0}$ powder. Treatment time $15 \mathrm{~min}, \mathrm{pH} \mathrm{3}$, air saturated solution, absorbance at $\lambda=$ $600 \mathrm{~nm}$.

The $\mathrm{pH}$ effect on the degradation of $\mathrm{RBB}$ by $\mathrm{Fe}^{0}$ is presented in Figure 5. In acid solutions the RBB removal efficiency varies from $80.1 \%$ to $98.2 \%$. The minimal dependence on the solution conditions contrasts favorably with the narrow optimal $\mathrm{pH}$ range normally observed for other treatment methods. ${ }^{29}$ The process was efficient over a broad $\mathrm{pH}$ range (between $\mathrm{pH} 1.0$ and 7.0), which is the most relevant range for natural water samples and many effluents. On the other hand, at higher $\mathrm{pH}$ values, an acute decrease in the RBB degradation was observed, mainly due to the hydrolysis of iron ions and deposition of iron oxides on the $\mathrm{Fe}^{0}$ surface, blocking the electron transfer between $\mathrm{Fe}^{0}$ and RBB. The most effective degradation of RBB by RWZVIP was observed at $\mathrm{pH} 3$ and this value was used in all further experiments.

The impact of initial dye concentration on color removal yield was studied by comparing the rate of absorbance decrease for a variety of concentrations of RBB. It was found that the apparent rate constant for decrease of the absorbance remained relatively constant for RBB concentrations ranging from 20 to $200 \mathrm{mg} \mathrm{L}^{-1}$. For higher concentrations the apparent rate constant

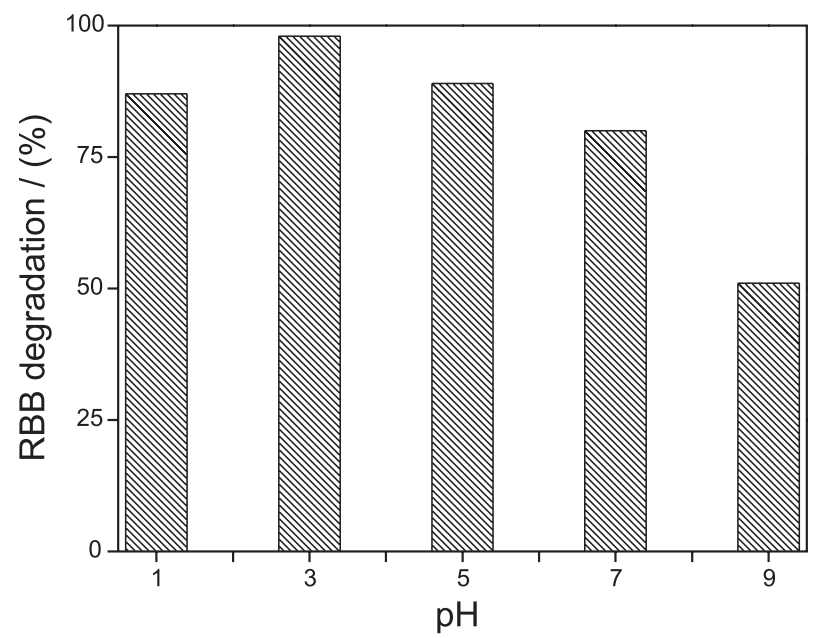

Figure 5. pH effect on degradation of a $100 \mathrm{mg} \mathrm{L}^{-1} \mathrm{RBB}$ solution by $\mathrm{Fe}^{0}$. Treatment time $15 \mathrm{~min}, 5 \mathrm{~g} \mathrm{~L}^{-1} 60$ mesh RWZVIP, air saturated solution, absorbance at $\lambda=600 \mathrm{~nm}$.

decreased considerably with increasing dye concentration (data not shown), further emphasizing the importance role of the RBB/RWZVIP ratio in determining the efficiency of reaction (compare Figure 4).

The degradation of a RBB solution was also examined under anaerobic $\left(\mathrm{N}_{2}\right.$ purged solution) and aerobic $\left(\mathrm{O}_{2}\right.$ purged solution $)$ conditions. As shown in Figure 6, a similar degree of RBB color removal by RWZVIP was observed under both conditions. In addition, both degradation conditions exhibit first order decay, with a linear dependence of $\ln \left(\mathrm{C} / \mathrm{C}_{0}\right)$ on time; the observed first order rate constants $\left(\mathrm{k}_{\mathrm{obs}}\right)$ were 0.146 $\pm 0.012 \mathrm{~min}^{-1}$ and $0.153 \pm 0.015 \mathrm{~min}^{-1}$ for anaerobic and aerobic conditions, respectively. These results suggest that the chromophore degradation step followed the same mechanism in these different media, probably involving $-\mathrm{N}=\mathrm{N}-$ group reduction. However, the presence or absence of oxygen had a strong influence on total organic carbon remotion. As can be seen from the comparative results in Figure 7, RBB mineralization occurs to a much higher degree in an aerobic medium than in a deoxygenated solution. When $\mathrm{O}_{2}$ was present in the RBB solution, significant TOC removal (around $70 \%$ ) was achieved in 60 minutes of treatment. On the other hand, during the same treatment time in the absence of $\mathrm{O}_{2}$, only $10 \%$ of the initial TOC was removed. Thermogravimetric analysis showed that $10 \%$ was the normal TOC loss due to adsorption onto the RWZVIP surface in the absence of any transformation/ degradation.

Previous studies ${ }^{17,21,27}$ have shown that $\mathrm{Fe}^{0}$ can oxidize organic compounds in the presence of oxygen. In this situation, dissolved oxygen is the preferred iron oxidant, resulting in rapid corrosion according to equation 1 . Thus, 

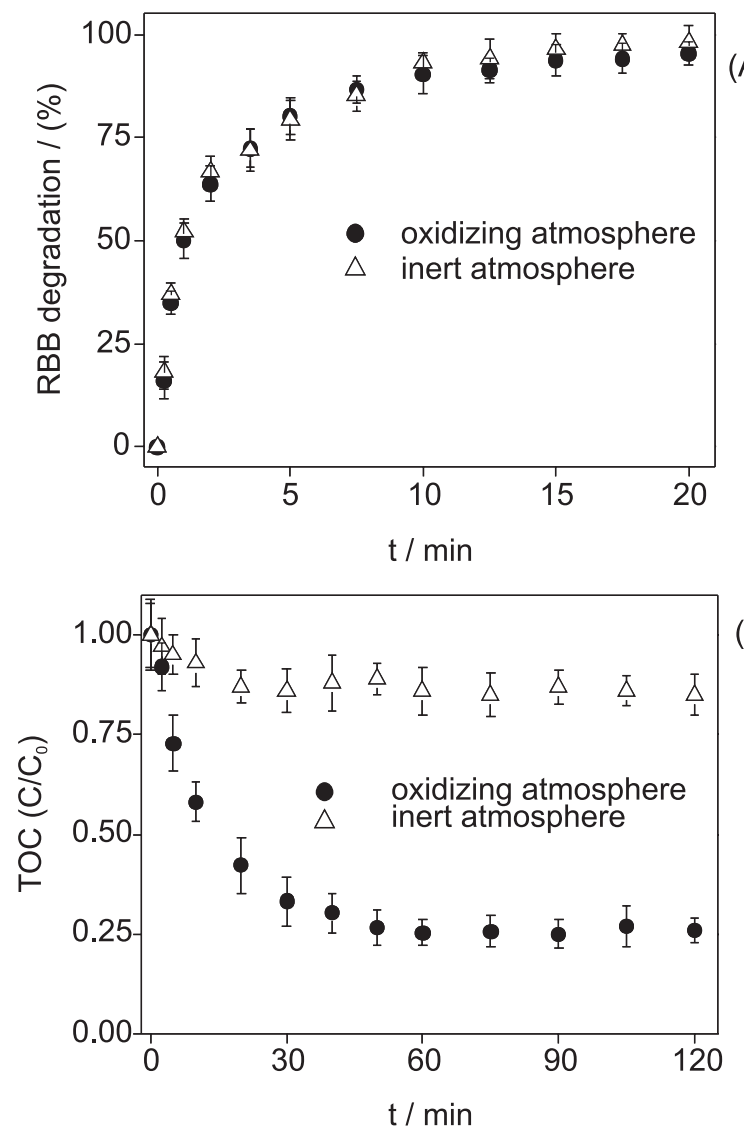

(B)

Figure 6. RBB concentration reduction $(\mathrm{A})$ and mineralization degree (B) as a function of treatment time by RWZVIP $\left(5 \mathrm{~g} \mathrm{~L}^{-1} 60\right.$ mesh RWZVIP) under inert and oxidizing atmospheres. Conditions: $\mathrm{pH}_{0} 3,[\mathrm{RBB}]_{0} 100$ $\mathrm{mg} \mathrm{L}^{-1}$, absorbance at $\lambda=600 \mathrm{~nm}$.

the first step in the oxidation of RBB by RWZVIP involves the oxidation of $\mathrm{Fe}^{0}$ by $\mathrm{O}_{2}$ (corrosion reaction). This reaction forms a reactive oxygen species either on the particle surface or in solution. ${ }^{27}$

$\mathrm{Fe}^{0}+\mathrm{O}_{2}+2 \mathrm{H}^{+} \rightleftarrows \mathrm{Fe}^{2+}+\mathrm{H}_{2} \mathrm{O}_{2}$

$\mathrm{H}_{2} \mathrm{O}_{2}$ produced in equation 1 could oxidize another $\mathrm{Fe}^{0}$ (equation 2) or react with species such as $\mathrm{Fe}^{2+}$ (equation 3). The latter is one of most studied advanced oxidation processes, the Fenton's process, which has been widely employed for the efficient degradation and mineralization of a broad range of organic pollutant compounds. ${ }^{10}$

$$
\begin{aligned}
& \mathrm{Fe}^{0}+\mathrm{H}_{2} \mathrm{O}_{2} \rightleftarrows \mathrm{Fe}^{3+}+2 \mathrm{OH}^{-} \\
& \mathrm{Fe}^{2+}+\mathrm{H}_{2} \mathrm{O}_{2} \rightleftarrows \mathrm{Fe}^{3+}+\mathrm{OH}^{\bullet}+\mathrm{OH}^{-}
\end{aligned}
$$

Actually, this mechanism involves several stages. The reduction of dissolved oxygen results in formation of superoxide radicals, $\mathrm{O}_{2}{ }^{*}$, which reacts in acid medium to produce $\mathrm{HO}_{2} \cdot{ }^{21}$ The disproportionation of this unstable species leads to hydrogen peroxide formation at or near to the $\mathrm{Fe}^{0}$ surface (equation 4$):^{17}$

$\mathrm{HO}_{2}+\mathrm{HO}_{2} \rightleftarrows \mathrm{H}_{2} \mathrm{O}_{2}+\mathrm{O}_{2}$

Reaction 1 is usually the dominant mechanism of $\mathrm{O}_{2}$ mediated corrosion and thus significant amounts of $\mathrm{H}_{2} \mathrm{O}_{2}$ can be produced. ${ }^{17,30}$ Consequently, hydroxyl radical (equation 3), one of the most potent oxidizing agents known ${ }^{7}$ can be formed and promote RBB mineralization via oxidation to inorganic carbon and nitrogen compounds. Such oxidactive mineralization cannot occur when there is only a reductive interaction between $\mathrm{Fe}^{0}$ and the organic pollutant.

The formation of $\mathrm{OH}^{*}$ radicals in the RWZVIP oxidation mechanism was evaluated by carrying out the RWZVIP treatment in an oxygenated aqueous solution of the dye containing 5\% $t$-butyl alcohol. It is well known that $t$-butyl alcohol acts as a scavenger of hydroxyl radicals, impeding the degradation of other organic compounds. ${ }^{10}$ Under these experimental conditions, the RBB mineralization is strongly decreased, falling to just $14 \pm 3 \%$ after 60 minutes of treatment (which is close to the basal level of TOC loss due to the adsorption of RBB on the $\mathrm{Fe}^{0}$ surface). This provides consistent evidence for the role of $\mathrm{OH}$ as the main oxidative agent for promoting the breakdown of RBB.

The oxidation of $\mathrm{Fe}^{0}$ by oxygen also results in the formation of a layer with properties similar to $\gamma-\mathrm{Fe}_{2} \mathrm{O}_{3}$ and $\mathrm{Fe}_{3} \mathrm{O}_{4}$ on the particle surface, which eventually leads to a reduction in the reactivity (or passivation) of the surface. ${ }^{17}$ This phenomenon could be observed by carrying out repetitive experiments with the very same RWZVIP portion. Under anaerobic conditions, after five treatment cycles (treatment time $=15 \mathrm{~min}$ ) the material maintained up to $75 \%$ of the RBB degradation efficiency. On the other hand, under aerobic conditions, the material lost its degradation activity after just two cycles.

Since the RWZVIP treatment under aerobic conditions showed an excellent potential for promoting degradation and mineralization of organic dyes, this process was also evaluated with a real complex matrix, a textile industrial effluent. Table 2 shows the initial characteristics of the effluent studied. Figure 8 shows the favorable effect of aerobic RWZVIP treatment on effluent decoloration, which usually represents a big challenge in conventional biological treatments. After just 50 minutes, more than $95 \%$ of the effluent color (absorbance at $\lambda=600 \mathrm{~nm}$ ) was removed. The process also resulted in an excellent degree of effluent mineralization, with ca. 50\% TOC removal in 60 minutes of treatment. 


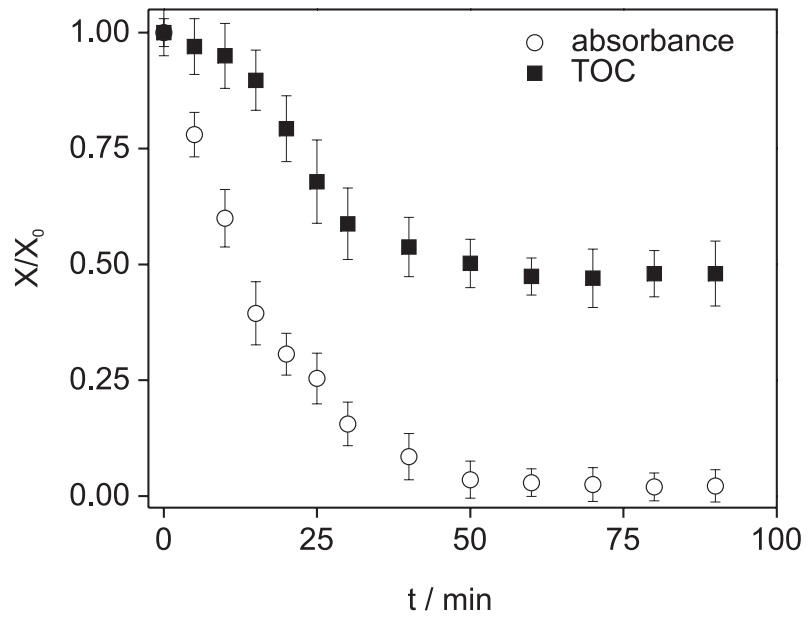

Figure 7. Results of textile effluent treatment by RWZVIP under an oxidizing atmosphere. Conditions: $5 \mathrm{~g} \mathrm{~L}^{-1} 60$ mesh RWZVIP, $\mathrm{pH}_{0} 3$, absorbance at $\lambda=600 \mathrm{~nm}$.

\section{Conclusions}

RWZVIP appears to be a very good iron source for this treatment. Besides its ability to promote rapid and efficient treatment of contaminated water, this non-toxic and inexpensive (or free) material can significantly reduce treatment costs by replacing expensive zero-valent iron. In addition, this utilization presents the additional advantage of reutilization of an industrial waste product as an active agent for the purification and conservation of the quality of water bodies.

Complete azo dye decoloration of an aqueous solution could be achieved in a few minutes by contacting the solution with recycled waste zero-valent iron powder under ambient conditions over a broad range of $\mathrm{pH}$. RBB decoloration could be described by first order reaction kinetics with rate constants $\left(\mathrm{k}_{\mathrm{obs}}\right)$ of $0.146 \mathrm{~min}^{-1}$ and 0.153 $\mathrm{min}^{-1}$ (for anaerobic and aerobic conditions, respectively) in the presence of $5 \mathrm{~g}$ of 60 mesh $\mathrm{Fe}^{0} \mathrm{~L}^{-1}$. This material showed a degradation efficiency similar to those exhibited by several with different commercial $\mathrm{Fe}^{0}$ sources. ${ }^{31-33}$

RBB degradation by RWZVIP could be carried out through reductive or oxidizing pathways, depending on the oxygen level and $\mathrm{pH}$. The former seems to be the preferential mechanism for azo dye chromophore degradation; the latter, which is due to in situ Fentonreactions, promotes effective mineralization of the dye.

The very favorable characteristics of this treatment were also evaluated in the remediation of a real textile effluent. Once again, RWZVIP showed excellent results, promoting a $50 \%$ reduction in the TOC of the textile effluent in just 60 minutes of treatment. However, before this technology can be fully optimized for environmental applications, further study is needed. Important questions currently under investigation include the establishment of the exact mechanisms and pathways of the observed organic transformations and the development of ways to enhance and stabilize the catalytic activity and recover the activity of oxidized iron.

\section{Acknowledgments}

The authors would like to acknowledge financial support from FAPESP and CNPq. The authors thank Prof. Frank Herbert Quina for the English revision.

\section{References}

1. Nigam, P.; Banat, I. M.; Singh, D.; Marchant, R.; Process Biochem. 1996, 31, 435.

2. Baban, A.; Yediler, A.; Lienert, D.; Kemerdere, N.; Kettrup, A.; Dyes Pigments 2003, 58, 93.

3. Perkowski, J.; Ledakowicz, S.; Fibres Text East Eur. 2002, 10, 72.

4. Waters, B. D. In Colour in Dyehouse Effluent; Cooper, P., ed.; Society of Dyers and Colourists: Bradford, 1995.

5. Pearce, C. I.; Lloyd, J. R.; Guthrie, J. T.; Dyes Pigments 2003, 58,179

6. Umbuzeiro, G D. A.; Freeman, H. S.; Warren, S. H.; de Oliveira, D. P.; Terao, Y.; Watanabe, T.; Claxton, L. D.; Chemosphere 2005, 60, 55 .

7. Legrini, 0.; Oliveros, E.; Braun, A. M.; Chem. Rev. 1993, 93, 671.

8. de Moraes, S. G.; Freire, R. S.; Duran, N.; Chemosphere 2000, 40, 369 .

9. Arslan-Alaton, I.; Color. Technol. 2003, 119, 345.

10. Gogate, P. R.; Pandit, A. B.; Adv. Environ. Res. 2004, 8, 501.

11. Domínguez, J. R.; Beltrán, J.; Rodríguez, O.; Catal. Today 2005 , 101, 389.

12. Gillham, R. W.; O’Hannesin, S. F.; Ground Water 1994, 32, 958.

13. Cheng, I. F.; Muftikian, R.; Fernando, Q.; Korte, N.; Chemosphere 1997, 35, 2689.

14. Syales, G. D.; You, G.; Wang, M.; Kupferle, M. J.; Environ. Sci. Technol. 1997, 31, 3448.

15. Klausen, J.; Ranke, J.; Schwarzenbach, R. P.; Chemosphere 2001, 44, 511.

16. Zang, W-X.; J. Nanopart. Res. 2003, 5, 323.

17. Joo, S. H.; Feitz, A. J.; Sedlak, D. L.; Waite, T. D.; Environ. Sci. Technol. 2005, 39, 1263.

18. Pereira, W. S.; Freire, R. S.; Quim. Nova 2005, 28, 130.

19. Bratsch, S. G.; J. Phys. Chem. Ref. Data 1989,18, 1.

20. Matheson, L. J.; Tratnyek, P. G.; Environ. Sci. Tecnhol. 1994, 28, 2045.

21. Roy, G.; DeDonato, P.; Gorner, T.; Barres, O.; Water Res. 2003, 37,4954 . 
22. Scherer, M. M.; Westall, J. C.; Ziomek-Moroz, M.; Tratnyek, P. G.; Environ. Sci. Tecnhol. 1997, 31, 2385.

23. Devlin, J. F.; Klausen, J.; Schwarzenbach, R. P.; Environ. Sci. Tecnhol. 1998, 32, 1941.

24. ISO - International Organization for Standarization; Guidelines for Determination of Total Organic Carbon (TOC) ISO-8245, 1987.

25. Ince, N. H.; Tezcanli, G.; Dyes Pigments 2001, 49, 145.

26. Scherer, M. M.; Johnson, K. M.; Westall, J. C.; Tratnyek, P. G.; Environ. Sci. Tecnhol. 2001, 35, 2804.

27. Rima, J.; Aoun, E.; Hanna, K.; Li, Q. X.; J. Phys. IV 2005, 124, 81.

28. Choe, S.; Chang, Y-Y.; Hwang, K-Y.; Khim, J.; Chemosphere 2000, 41, 1307
29. Pera-Titus, M.; Garcia-Molina, V.; Banos, M. A.; Gimenez, J.; Esplugas, S.; Appl. Catal. B-Environ. 2004, 47, 219.

30. Oturan, M. A.; J. Appl. Electrochem. 2000, 30, 475.

31. Deng, N.; Luo, F.; Wu, F.; Xiao, M.; Wu, X.; Water Res. 2000 , 34, 2408

32. Nam, S.; Tratnyek, P. G.; Water Res. 2000, 34, 1837.

33. Mu, Y.; Yu, H. Q.; Zhang, S. J.; Zheng, J. C.; J. Chem. Technol. Biot. 2004, 79, 1429.

Received: January 16, 2006 Published on the web: June 12, 2006

FAPESP helped in meeting the publication costs of this article. 